Article

\title{
Anti-Inflammatory Effects of Jakyakgamcho-Tang in IL-4- and TNF- $\alpha$-Stimulated Lung Epithelial Cells and Lipopolysaccharide-Stimulated Macrophages
}

\author{
Yu Jin Kim (D), Woo-Young Jeon, Mee-Young Lee, Youn-Hwan Hwang * ${ }^{\mathbb{D}}$ and Jinhee Kim * \\ KM Convergence Research Division, Korea Institute of Oriental Medicine, 1672 Yuseong-daero, Yuseong-gu, \\ Daejeon 34054, Korea; jinjin0228@kiom.re.kr (Y.J.K.); ssamggun85@kiom.re.kr (W.-Y.J.); \\ cozy11@kiom.re.kr (M.-Y.L.) \\ * Correspondence: hyhhwang@kiom.re.kr (Y.-H.H.); jinheekim@kiom.re.kr (J.K.); \\ Tel.: +82-42-868-9260 (Y.-H.H.); +82-42-868-9249 (J.K.)
}

check for updates

Citation: Kim, Y.J.; Jeon, W.-Y.; Lee, M.-Y.; Hwang, Y.-H.; Kim, J.

Anti-Inflammatory Effects of

Jakyakgamcho-Tang in IL-4- and

TNF- $\alpha$-Stimulated Lung Epithelial

Cells and Lipopolysaccharide-

Stimulated Macrophages. Appl. Sci.

2021, 11, 10569. https://doi.org/

10.3390/app112210569

Academic Editor: João Rocha

Received: 30 August 2021

Accepted: 5 November 2021

Published: 10 November 2021

Publisher's Note: MDPI stays neutral with regard to jurisdictional claims in published maps and institutional affiliations.

Copyright: (c) 2021 by the authors. Licensee MDPI, Basel, Switzerland. This article is an open access article distributed under the terms and conditions of the Creative Commons Attribution (CC BY) license (https:// creativecommons.org/licenses/by/ $4.0 /)$.

\begin{abstract}
Asthma is a chronic respiratory disease mediated by airway inflammation. Jakyakgamchotang (JGT), a traditional medicine, is widely subscribed to common diseases such as muscle pain and cramps in East Asian countries. Although the efficacy of JGT on peripheral neuropathy, gouty arthritis, and colitis has been reported, the effect of JGT on airway inflammation related to asthma is not clearly investigated. In this study, we aimed to evaluate the effects of JGT water extract (JGTW) on factors related to airway inflammation using the human bronchial epithelial BEAS-2B and the mouse monocyte-macrophage RAW264.7 cell lines. Furthermore, the constituents in JGTW were quantitatively and qualitatively studied for future reference of JGTW standardization. JGTW reduced the generation of several airway inflammation mediators such as eotaxins, regulated on activation normal T-cell expressed and secreted (RANTES), and matrix metalloproteinase-9, and expressions of adhesion molecules (ICAM-1 and VCAM-1), which attracts leukocytes to the site of inflammation in interleukin- 4 + tumor necrosis factor- $\alpha$ (IT)-stimulated BEAS-2B cells. In lipopolysaccharidestimulated RAW264.7 cells, JGTW effectively suppressed inducible nitric oxide synthase (iNOS) induction by inhibiting the MAPK and NF- $\mathrm{KB}$ signaling. In addition, JGTW treatment showed decreased inflammatory cells and Th2 cytokines in bronchoalveolar lavage fluid and decreased IgE levels in plasma in the OVA-induced asthmatic mice model. In the ultra-performance liquid chromatography-diode array detector-tandem mass spectrometry analysis, 24 phytochemicals were identified in JGTW, and paeoniflorin $(63.971 \mathrm{mg} / \mathrm{g})$ and glycyrrhizin $(11.853 \mathrm{mg} / \mathrm{g}$ ) were found to be the most abundant. These findings suggest that JGTW has anti-inflammatory effects on airway inflammation by regulating inflammatory response-related factors, possibly through MAPK and NF- $\kappa \mathrm{B}$ in pulmonary epithelial cells and macrophages.
\end{abstract}

Keywords: Jakyakgamcho-tang; bronchial epithelial cell; macrophage; airway inflammation; UPLC-DAD-MS/MS

\section{Introduction}

Asthma is a chronic respiratory disease known to be caused by excessive airway inflammation and hyper-responsiveness that leads to obstruction of airway [1]. Airway inflammation in asthma is induced by complex regulatory mechanisms involving the release of T helper 2 (Th2) cytokines (interleukin (IL)-4, IL-5, and IL-13), chemokines (eotaxins and regulated on activation, normal T-cell expressed and secreted (RANTES)), and other signaling molecules such as nitric oxide (NO) [2,3]. Inflammatory cells, including eosinophil, mast cells and macrophages, contribute to the release of Th2 cytokines, chemokines, and tumor necrosis factor- $\alpha$ (TNF- $\alpha)$, a pro-inflammatory cytokine [4]. These soluble inflammatory mediators activate other proteins such as matrix metalloproteinase 9 (MMP-9), leading to degradation of the extracellular matrix, making respiratory microenvironment easier for 
inflammatory cells to infiltrate [5]. The infiltration of inflammatory cells occurs because leukocytes increase adhesion to pulmonary epithelial cells by increasing the expression of adhesion molecules on the surface of cells [6]. Overexpression of adhesion molecules, such as intercellular adhesion molecule-1 (ICAM-1) and vascular cell adhesion molecule-1 (VCAM-1), in airway epithelial cells is associated with infiltration of inflammatory cells, which is implicated in the pathogenesis of airway inflammatory diseases like asthma [7]. Therefore, regulating these inflammatory mediators in pulmonary epithelial cells could help alleviate airway inflammation leading to relieving symptoms of asthma and other respiratory diseases.

Macrophages are the predominant immune cells in the lungs and play a key role in airway inflammation and hyper-responsiveness in asthma by balancing inflammatory and anti-inflammatory responses $[8,9]$. As reducing inflammation is one of the primary goals in the treatment of asthma, suppressing inflammatory responses of macrophages is beneficial for reducing symptoms of asthma.

Traditionally, herbal medicine has been used to treat various diseases, although it has been evaluated as lacking scientific evidence for application to indications in modern medicine. Still, there is a demand to find new indications using existing herbal medicine prescriptions due to its proven safety of years of common usage. The main purpose of our study project is to investigate the effectiveness of herbal medicines widely used in Korea in relieving symptoms related to asthma, such as airway inflammation.

Jakyakgamcho-tang (JGT), also known as Shaoyao-gancao-tang in Chinese and Shakuyakukanzo-to in Japanese, is a traditional medicine commonly used in Korea, China, and Japan. JGT contains two herbal ingredients, Paeonia lactiflora Pall. (root) and Glycyrrhiza uralensis Fisch. (root and rhizome), in a ratio of 1:1 (w/w). JGT is widely used to treat smooth muscle contractions-related abdominal pain and skeletal muscle spasms-related cramps $[10,11]$. It has been reported that JGT exhibits inhibitory effects on smooth muscle contractions [12], gouty arthritis animal models [13], therapeutic effects on colitis by regulating gut microbiota [14] and painful peripheral neuropathy [15], and anti-glycation properties [16]; moreover, it is effective in reducing muscle soreness after exercise [17]. Although JGT has been reported to regulate the imbalance of Th17 and regulatory T-cell (Treg) responses in asthma [18], the detailed investigation of the anti-asthmatic effects of JGT is still lacking.

In the present study, we explored the effect of JGT water extract (JGTW) on factors related to airway inflammation, a hallmark of asthma, in the human bronchial epithelial BEAS-2B and in the murine macrophage RAW264.7 cell lines to seek the clinical potential of JGT to relieve the symptoms of asthma. We also examined the effect of JGTW on the pulmonary inflammation and allergic response in a mouse model of asthma induced by ovalbumin (OVA). In addition, the ultra-performance liquid chromatography-diode array detector-tandem mass spectrometry (UPLC-DAD-MS/MS) analysis was performed for qualitative and quantitative analysis of major components in JGTW.

\section{Materials and Methods}

\subsection{Plant Materials and Preparation of Extract}

The JGTW was distributed by the KM Convergence Research Division of the Korea Institute of Oriental Medicine (Daejeon, Korea). The hot water extraction method of plant material is described in detail in a previous study [19].

\subsection{Preparation of Sample and Standard Solutions for UPLC-DAD-MS/MS Analysis}

JGTW solution was prepared at a concentration of $0.05,0.1,0.5$, and $20 \mathrm{mg} / \mathrm{mL}$ in methanol and filtered using a $0.2-\mu \mathrm{m}$ syringe filter. The 24 reference standards (purity $>95 \%$ ), namely catechin, vicenin-2, schaftoside, isoschaftoside, neoliquiritin, liquiritin, luteolin, liquiritigenin, calycosin, naringenin, kaempferol, formononetin, licochalcone $\mathrm{B}$, echinatin, isoliquiritigenin, albiflorin, paeoniflorin, mudanpioside $\mathrm{C}$, benzoylpaeoniflorin, glycyrrhizin, hederagenin, and glycyrrhetinic acid (ChemFaces Biochemical Co., 
Ltd., Wuhan, China), taxifolin (ICN Biochemicals, Aurora, OH, USA), and 1,2,3,4,6-Opentagalloylglucose (Biopurify Phytochemicals, Chengdu, China) were used to identify and quantify the phytochemicals in JGTW. LC-MS grade solvents were purchased from Thermo Fisher Scientific (Waltham, MA, USA). The 24 reference standards were prepared in methanol at final concentrations ranging from $0.02-10 \mu \mathrm{g} / \mathrm{mL}$, except for vicenin-2 $(0.001-0.595 \mu \mathrm{g} / \mathrm{mL})$ and echinatin $(0.001-0.27 \mu \mathrm{g} / \mathrm{mL})$.

\subsection{UPLC and MS Conditions}

To identify chemical constituents in JGTW, a Dionex UltiMate 3000 system Thermo Q-Exactive mass spectrometer (Thermo Fisher Scientific, Waltham, MA, USA) was used. UPLC-DAD-MS/MS analysis was conducted using a modified method proposed in a previous study [20]. The compounds were separated using an Acquity BEH $\mathrm{C}_{18}$ column $\left(100 \mathrm{~mm} \times 2.1 \mathrm{~mm}, 1.7 \mu \mathrm{m}\right.$, Waters, Milford, MA, USA) at $40{ }^{\circ} \mathrm{C}$ by gradient elution of the two mobile phases, $0.1 \%(v / v)$ aqueous formic acid (A) and acetonitrile (B) as follows: $3 \% \mathrm{~B}$ for $0-1 \mathrm{~min}, 3-10 \%$ B for $1-2 \mathrm{~min}, 10-30 \%$ B for $2-10 \mathrm{~min}, 30-40 \%$ B for $10-15 \mathrm{~min}, 40-100 \%$ B for $15-20 \mathrm{~min}, 100 \% \mathrm{~B}$ for $20-23 \mathrm{~min}$, and $3 \%$ B for $24-28 \mathrm{~min}$. The injection volume and flow rates were $3 \mu \mathrm{L}$ and $0.25 \mathrm{~mL} / \mathrm{min}$, respectively. Mass spectra were acquired in both positive and negative electrospray ionization (ESI) modes. The MS/MS conditions are described in a previous study [21]. The mass spectra were recorded in the range of $100-1500 \mathrm{~m} / \mathrm{z}$, with a collision energy of $25 \mathrm{eV}$. Data-dependent acquisition using a full MS-ddMS ${ }^{2}$ setup was used. The acquired data were processed using Xcalibur v.3.0 and TraceFinder v.3.2 software (Thermo Fisher Scientific, Waltham, MA, USA).

\subsection{Cell Culture}

BEAS-2B and RAW264.7 cell lines were purchased from American Type Culture Collection (Rockville, MD, USA) and maintained in suggested media containing $10 \%$ fetal bovine serum (FBS; Gibco, New York, NY, USA) supplemented with $100 \mathrm{U} / \mathrm{mL}$ penicillin and $100 \mu \mathrm{g} / \mathrm{mL}$ streptomycin (Gibco, New York, NY, USA) at $37^{\circ} \mathrm{C}$ in a humidified incubator with $5 \% \mathrm{CO}_{2}$.

\subsection{Cytotoxicity Assay}

Cell viability was assessed using the cell counting kit (CCK)-8 assay (Dojindo, Kumamoto, Japan). BEAS-2B cells $\left(6 \times 10^{3}\right.$ cells/well) were incubated in 96-well plates with $31.25,62.5,125,250$ and $500 \mu \mathrm{g} / \mathrm{mL}$ of JGTW for $24 \mathrm{~h}$. The cytotoxicity assay was conducted as described previously [21].

2.6. Measurement of Chemokine Production, MMP Activity, and Adhesion Molecule Expression in BEAS-2B Cells

BEAS-2B cells $\left(5 \times 10^{5}\right.$ cells / well) were cultured in six-well plates overnight, then washed and incubated with of serum-free medium containing $50 \mathrm{ng} / \mathrm{mL}$ of IL- $4+$ TNF- $\alpha$ (IT; R\&D Systems Inc., Minneapolis, MN, USA). After 48 h, culture supernatants were collected to measure the productions of eotaxin-3, eotaxin-1, and RANTES using and enzyme-linked immunosorbent assay (ELISA) and MMP-9 activity zymography as described previously [21]. The remaining cells were harvested to get the total RNA for measuring the expression levels of adhesion molecules (ICAM-1 and VCAM-1) and housekeeping gene, glyceraldehyde-3-phosphate dehydrogenase (GAPDH). The detailed description of materials and experimental conditions for the RT-PCR have been described earlier [21].

\subsection{Measurement of NO in LPS-Stimulated RAW264.7 Cells}

Nitrite concentration was used as a measure of NO production in LPS-stimulated RAW264.7 cells. Cells were plated onto 96-swell plate at a density of $2 \times 10^{4}$ cells/well and pretreated with various concentrations of JGTW for $1 \mathrm{~h}$ and stimulated with $1 \mu \mathrm{g} / \mathrm{mL}$ LPS. After $24 \mathrm{~h}$ of incubation, the culture supernatants were collected for measuring nitrite 
concentrations using the Griess reagent (Promega, Madison, WI, USA), following the manufacturer's instructions.

\subsection{Western Blot Analysis}

RAW264.7 cells were pretreated with various concentrations of JGTW for $1 \mathrm{~h}$, stimulated with $1 \mu \mathrm{g} / \mathrm{mL}$ LPS for $24 \mathrm{~h}$, washed with cold PBS, and lysed in cold RIPA cell lysis buffer containing Halt protease and a phosphatase inhibitor cocktail (Thermo Scientific, Rockford, IL, USA). The total protein concentration was determined using a BCA assay kit (Thermo Scientific, Rockford, IL, USA), and $20 \mu \mathrm{g}$ of total protein from each lysate was loaded and separated by SDS-PAGE and blotted onto PVDF membranes (ATTO Corporation, Tokyo, Japan). The membranes were blocked with EzBlockChemi (ATTO Corporation), probed with designated primary antibodies overnight, and incubated with horseradish peroxidase-conjugated secondary antibodies for $1 \mathrm{~h}$. Bound antibodies were visualized with Supersignal West Femto Maximum sensitivity substrate (Thermo Scientific, Rockford, IL, USA).

\subsection{OVA-Induced Asthmatic Mice}

Specific pathogen-free (SPF) BALB/c female mice (six weeks of age) were purchased from Orientbio Inc. (Seongnam, Korea). Animals were maintained in environmentally controlled SPF conditions and were provided with a standard diet and water ad libitum. All experimental procedures were approved by the Animal Experimental Ethics Committee of Chungnam National University (Daejeon, Korea). Asthma is induced by ovalbumin (OVA; Sigma-Aldrich, St. Louis, MO, USA). Mice were randomly divided into five groups (five animals per group): NC (normal control group), OVA (OVA-induction group), Dex (dexamethasone: OVA-induction + Dex at $1 \mathrm{mg} / \mathrm{kg}$ ), JGTW-200 (OVA-induction + JGTW at $200 \mathrm{mg} / \mathrm{kg}$ ), and JGTW-400 (OVA-induction + JGTW at $400 \mathrm{mg} / \mathrm{kg}$ ). Dex (Sigma-Aldrich) was used as a positive control for relieving symptoms of allergic responses. BALB/c mice were sensitized on days 1,8 , and 15 via an intraperitoneal injection of OVA (50 $\mu \mathrm{g})$ emulsified with $4 \mathrm{mg}$ of Imject ${ }^{\circledR}$ alum adjuvant (Thermo Fisher Scientific Inc., Waltham, MA, USA). Two weeks after the last sensitization, the mice were injected intranasally with OVA solution $(1 \mathrm{mg} / \mathrm{mL})$ on days $28,31,33$. JGTW groups was administered by gavage to mice at doses of 200 or $400 \mathrm{mg} / \mathrm{kg}$ once daily from days 24 to 33 . The NC, OVA, or Dex groups were administered distilled water or Dex orally, respectively. Two days after the last exposure, mice were sacrificed by intraperitoneal injection of pentobarbital, and tracheostomy was conducted to get bronchoalveolar lavage fluid (BALF). The total inflammatory cells in BALF were evaluated by counting in at least 4 squares of a hemocytometer (C-Chip, NanoEnTek, Seoul, Korea). Plasma obtained by cardiac puncture was used for subsequent analysis.

\subsection{Measurement of IL-5, IL-13 and IgE Levels in BALF and Plasma}

The levels of IL-5 and IL-13 (R\&D Systems Inc.) in BALF; levels of total and OVAspecific immunoglobulin E (IgE; BioLegend, San Diego, CA, USA) in plasma were measured using ELISA kits following the manufacturer's instructions.

\subsection{Statistical Analyses}

The values are presented as mean \pm standard error of the mean (SEM) or standard deviation (SD). Differences among means were analyzed using one-way analysis of variance (ANOVA) followed by a Dunnett's post-hoc test. $p$-values of $<0.05$ were considered to be statistically significant.

\section{Results}

\subsection{UPLC-DAD-MS/MS Analysis of JGTW}

UPLC-DAD-MS/MS analysis was conducted to identify and quantify the phytochemicals in JGTW. The 24 compounds were separated on an Acquity BEH $\mathrm{C}_{18}$ column $\left(100 \mathrm{~mm} \times 2.1 \mathrm{~mm}, 1.7 \mu \mathrm{m}\right.$, Waters) at $40{ }^{\circ} \mathrm{C}$ within $22 \mathrm{~min}$. The both (+)-ESI and (-)- 
ESI modes were operated to acquire the MS spectra. The characteristics of all identified compounds in JGTW are summarized in Table 1. UV and base peak chromatograms of JGTW are presented in Figure 1A, and the extracted ion chromatograms for each phytochemical are shown in Figure 1B. Most compounds were identified in negative ion mode. The precursor ions and MS/MS fragment patterns of the phytochemicals were identified by comparisons with the mass spectra and retention times of reference standards (Supplementary Materials Figure S1). The contents of the 20 phytochemicals, except for schaftoside, isoschaftoside, neoliquiritin, and liquiritin, ranged from 0.001 to $63.971 \mathrm{mg} / \mathrm{g}$. In EICs of several constituents (e.g., catechin, luteolin, echinatin, glycyrrhizin) of JGTW, multiple peaks with the same $\mathrm{m} / \mathrm{z}$ that have different retention times were observed, considering their isomers and derivatives. Further study is required for the structural confirmation of identified constituents isolated from JGTW in detail.

Table 1. Identification of phytochemicals in JGTW using UPLC-DAD-MS/MS.

\begin{tabular}{|c|c|c|c|c|c|c|c|c|c|}
\hline No. & $\begin{array}{c}\text { RT } \\
(\mathrm{min})\end{array}$ & $\begin{array}{l}\text { Calculated } \\
\qquad(m / z)\end{array}$ & $\begin{array}{l}\text { Estimated } \\
\qquad(\mathrm{m} / \mathrm{z})\end{array}$ & Adduct & $\begin{array}{l}\text { Error } \\
(\mathrm{ppm})\end{array}$ & Formula & $\begin{array}{l}\text { MS/MS Fragments } \\
\qquad(\mathrm{m} / \mathrm{z})\end{array}$ & Identifications & $\begin{array}{c}\text { Contents } \\
(\mathrm{mg} / \mathrm{g})\end{array}$ \\
\hline \multicolumn{10}{|c|}{ Flavonoids } \\
\hline 1 & 5.94 & 289.0718 & 289.0717 & {$[\mathrm{M}-\mathrm{H}]^{-}$} & 0.377 & $\mathrm{C}_{15} \mathrm{H}_{14} \mathrm{O}_{6}$ & $\begin{array}{c}289.0707,245.0808 \\
205.0492,179.0334 \\
125.0225\end{array}$ & Catechin [22] & 0.833 \\
\hline 2 & 6.91 & 593.1512 & 593.1516 & {$[\mathrm{M}-\mathrm{H}]^{-}$} & 1.019 & $\mathrm{C}_{27} \mathrm{H}_{30} \mathrm{O}_{15}$ & $\begin{array}{l}\text { 593.1500, 503.1207, } \\
473.1066,413.0872, \\
383.0770,354.0663\end{array}$ & Vicenin-2 [22] & 0.102 \\
\hline 3 & 7.63 & 563.1406 & 563.1406 & {$[\mathrm{M}-\mathrm{H}]^{-}$} & 0.316 & $\mathrm{C}_{26} \mathrm{H}_{28} \mathrm{O}_{14}$ & $\begin{array}{l}473.1069,443.0968 \\
383.0760,353.0656\end{array}$ & $\begin{array}{c}\text { Isoschaftoside } \\
\text { or Schaftoside } \\
\text { [22] }\end{array}$ & - \\
\hline 4 & 8.65 & 419.1337 & 419.1338 & {$[\mathrm{M}+\mathrm{H}]^{+}$} & 0.308 & $\mathrm{C}_{21} \mathrm{H}_{22} \mathrm{O}_{9}$ & 257.0808 & $\begin{array}{c}\text { Neoliquiritin } \\
{[22]}\end{array}$ & - \\
\hline 5 & 8.80 & 417.1191 & 417.1192 & {$[\mathrm{M}-\mathrm{H}]^{-}$} & 0.512 & $\mathrm{C}_{21} \mathrm{H}_{22} \mathrm{O}_{9}$ & $\begin{array}{l}\text { 417.1173, 255.0651, } \\
135.0069,119.0481\end{array}$ & Liquiritin [22] & - \\
\hline 6 & 8.93 & 303.0510 & 303.0509 & {$[\mathrm{M}-\mathrm{H}]^{-}$} & 0.287 & $\mathrm{C}_{15} \mathrm{H}_{12} \mathrm{O}_{7}$ & $\begin{array}{l}285.0392,275.0558 \\
259.0611,217.0493 \\
177.0177,125.0224\end{array}$ & Taxifolin [23] & 0.005 \\
\hline 7 & 11.92 & 255.0663 & 255.0660 & {$[\mathrm{M}-\mathrm{H}]^{-}$} & 0.136 & $\mathrm{C}_{15} \mathrm{H}_{12} \mathrm{O}_{4}$ & $\begin{array}{c}255.0652,135.0069 \\
119.0483\end{array}$ & $\begin{array}{c}\text { Liquiritigenin } \\
\text { [22] }\end{array}$ & 0.173 \\
\hline 8 & 12.29 & 285.0405 & 285.0405 & {$[\mathrm{M}-\mathrm{H}]^{-}$} & 0.022 & $\mathrm{C}_{15} \mathrm{H}_{10} \mathrm{O}_{6}$ & $\begin{array}{c}285.0393,241.0500 \\
217.0493,151.0022 \\
135.0433\end{array}$ & Luteolin [22] & 0.001 \\
\hline 9 & 12.53 & 285.0758 & 285.0760 & {$[\mathrm{M}+\mathrm{H}]^{+}$} & 0.731 & $\mathrm{C}_{16} \mathrm{H}_{12} \mathrm{O}_{5}$ & $285.0757,270.0525$ & Calycosin [22] & 0.007 \\
\hline 10 & 13.91 & 271.0612 & 271.0612 & {$[\mathrm{M}-\mathrm{H}]^{-}$} & -0.158 & $\mathrm{C}_{15} \mathrm{H}_{12} \mathrm{O}_{5}$ & $\begin{array}{l}271.0604,177.0177 \\
165.0181,151.0019\end{array}$ & Naringenin [22] & 0.018 \\
\hline 11 & 14.23 & 285.0405 & 285.0403 & {$[\mathrm{M}-\mathrm{H}]^{-}$} & 0.343 & $\mathrm{C}_{15} \mathrm{H}_{10} \mathrm{O}_{6}$ & $\begin{array}{c}285.0396,167.0332 \\
109.0275\end{array}$ & Kaempferol [22] & 0.002 \\
\hline 12 & 16.28 & 269.0808 & 269.0809 & {$[\mathrm{M}+\mathrm{H}]^{+}$} & 0.344 & $\mathrm{C}_{16} \mathrm{H}_{12} \mathrm{O}_{4}$ & $\begin{array}{c}269.0807,254.0577 \\
237.0548\end{array}$ & $\begin{array}{l}\text { Formononetin } \\
\text { [22] }\end{array}$ & 0.024 \\
\hline \multicolumn{10}{|c|}{ Chalcones } \\
\hline 13 & 11.67 & 285.0768 & 285.0768 & {$[\mathrm{M}-\mathrm{H}]^{-}$} & -0.131 & $\mathrm{C}_{16} \mathrm{H}_{14} \mathrm{O}_{5}$ & $285.0758,270.0524$ & $\begin{array}{c}\text { Licochalcone B } \\
\text { [22] }\end{array}$ & 0.024 \\
\hline 14 & 13.95 & 271.0965 & 271.0965 & {$[\mathrm{M}+\mathrm{H}]^{+}$} & 0.024 & $\mathrm{C}_{16} \mathrm{H}_{14} \mathrm{O}_{4}$ & $271.0962,121.0287$ & Echinatin [22] & 0.021 \\
\hline 15 & 15.67 & 255.0663 & 255.0661 & {$[\mathrm{M}-\mathrm{H}]^{-}$} & 0.495 & $\mathrm{C}_{15} \mathrm{H}_{12} \mathrm{O}_{4}$ & $\begin{array}{c}255.0653,135.0070 \\
119.0483\end{array}$ & $\begin{array}{l}\text { Isoliquiritigenin } \\
\text { [22] }\end{array}$ & 0.022 \\
\hline \multicolumn{10}{|c|}{ Terpenoids } \\
\hline 16 & 7.51 & 481.1704 & 481.1705 & {$[\mathrm{M}+\mathrm{H}]^{+}$} & 0.509 & $\mathrm{C}_{23} \mathrm{H}_{28} \mathrm{O}_{11}$ & $\begin{array}{c}197.0808,151.0754 \\
133.0650\end{array}$ & Albiflorin [22] & 4.323 \\
\hline 17 & 7.95 & 525.1614 & 525.1614 & {$\left[\mathrm{M}+\mathrm{HCO}_{2}\right]^{-}$} & -0.200 & $\mathrm{C}_{23} \mathrm{H}_{28} \mathrm{O}_{11}$ & $\begin{array}{c}328.1104,165.0539 \\
121.0275\end{array}$ & Paeoniflorin [22] & 63.971 \\
\hline 18 & 11.53 & 599.1770 & 599.1774 & {$[\mathrm{M}-\mathrm{H}]^{-}$} & 0.700 & $\mathrm{C}_{30} \mathrm{H}_{32} \mathrm{O}_{13}$ & $\begin{array}{l}477.1277,429.1172 \\
137.0226,121.0276\end{array}$ & $\begin{array}{c}\text { Mudanpioside C } \\
\text { [22] }\end{array}$ & 0.029 \\
\hline 19 & 14.13 & 629.1876 & 629.1876 & {$\left[\mathrm{M}+\mathrm{HCO}_{2}\right]^{-}$} & 0.455 & $\mathrm{C}_{30} \mathrm{H}_{32} \mathrm{O}_{12}$ & $165.0544,121.0276$ & $\begin{array}{l}\text { Benzoylpaeoniflorin } \\
\text { [22] }\end{array}$ & 1.464 \\
\hline
\end{tabular}


Table 1. Cont.

\begin{tabular}{|c|c|c|c|c|c|c|c|c|c|}
\hline No. & $\underset{(\mathrm{min})}{\mathrm{RT}}$ & $\begin{array}{l}\text { Calculated } \\
\quad(\mathrm{m} / \mathrm{z})\end{array}$ & $\begin{array}{l}\text { Estimated } \\
(\mathrm{m} / \mathrm{z})\end{array}$ & Adduct & $\begin{array}{l}\text { Error } \\
(\mathrm{ppm})\end{array}$ & Formula & $\begin{array}{l}\text { MS/MS Fragments } \\
\qquad(\mathrm{m} / \mathrm{z})\end{array}$ & Identifications & $\begin{array}{c}\text { Contents } \\
(\mathrm{mg} / \mathrm{g})\end{array}$ \\
\hline 20 & 17.69 & 821.3965 & 821.3967 & {$[\mathrm{M}-\mathrm{H}]^{-}$} & 0.563 & $\mathrm{C}_{42} \mathrm{H}_{62} \mathrm{O}_{16}$ & $\begin{array}{c}821.3934,351.0559 \\
193.0337\end{array}$ & $\begin{array}{c}\text { Glycyrrhizin } \\
\text { [22] }\end{array}$ & 11.853 \\
\hline 21 & 20.67 & 471.3480 & 471.3480 & {$[\mathrm{M}-\mathrm{H}]^{-}$} & -0.039 & $\mathrm{C}_{30} \mathrm{H}_{48} \mathrm{O}_{4}$ & - & $\begin{array}{c}\text { Hederagenin } \\
{[22]}\end{array}$ & 0.005 \\
\hline 22 & 21.19 & 471.3469 & 471.3471 & {$[\mathrm{M}+\mathrm{H}]^{+}$} & 0.072 & $\mathrm{C}_{30} \mathrm{H}_{46} \mathrm{O}_{4}$ & $\begin{array}{l}\text { 471.3470, 454.3427, } \\
407.3318,189.1641\end{array}$ & $\begin{array}{l}\text { Glycyrrhetinic } \\
\text { acid [22] }\end{array}$ & 0.007 \\
\hline 23 & 9.02 & 939.1109 & 939.1111 & {$[\mathrm{M}-\mathrm{H}]^{-}$} & 1.236 & $\begin{array}{l}\text { Phenol } \\
\qquad \mathrm{C}_{41} \mathrm{H}_{32} \mathrm{O}_{26}\end{array}$ & $\begin{array}{c}\text { 769.0868, 617.0763, } \\
447.0572,295.0449 \\
169.0125\end{array}$ & $\begin{array}{c}\text { 1,2,3,4,6-O- } \\
\text { Pentagalloylglucose } \\
\text { [22] }\end{array}$ & 2.634 \\
\hline
\end{tabular}
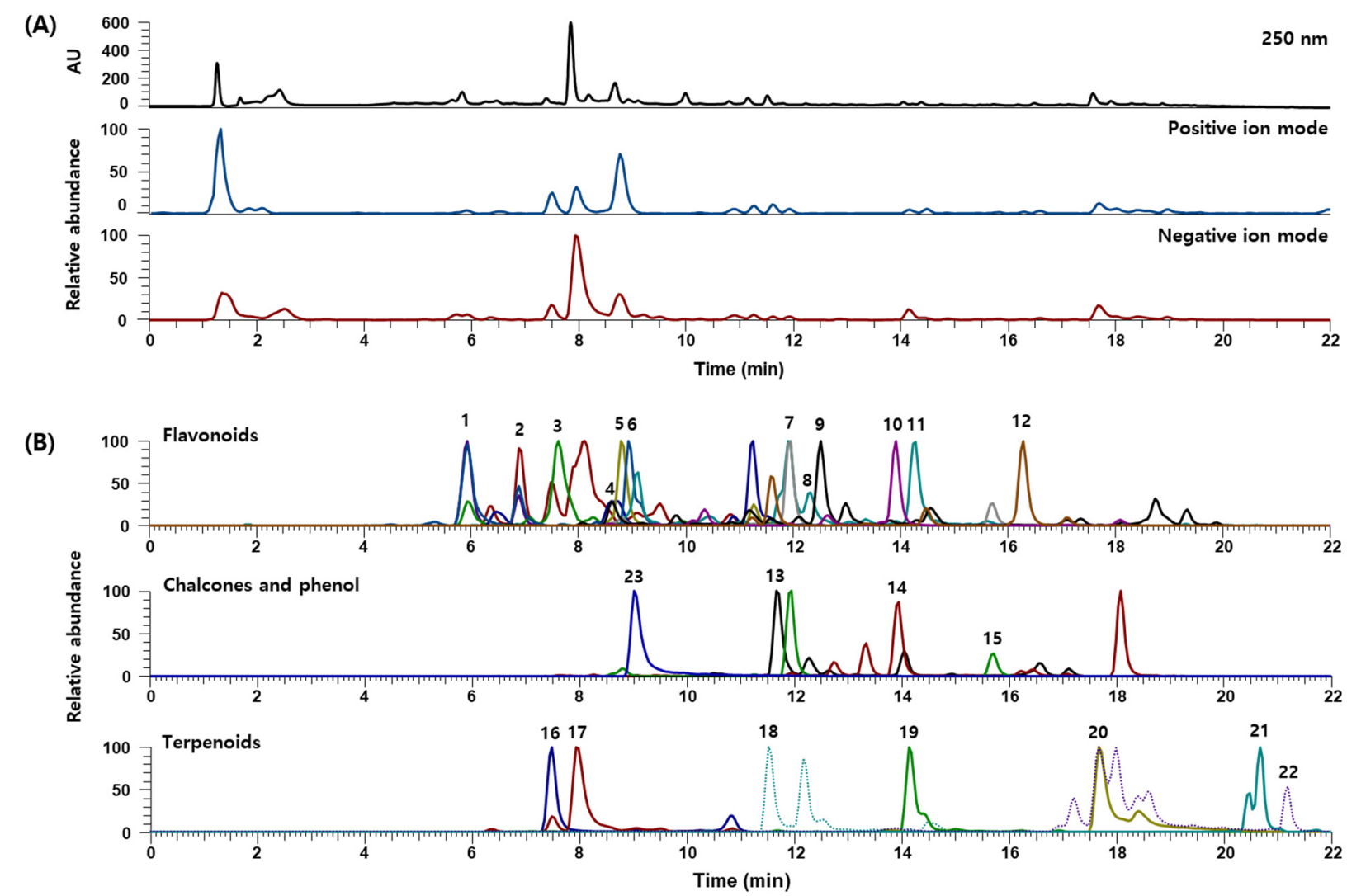

Figure 1. UPLC-DAD-MS/MS analysis of JGTW. (A) UV and base peak ion chromatograms of JGTW and (B) extracted ion chromatogram of the identified phytochemicals in JGTW. 1: catechin; 2: vicenin-2; 3: schaftoside or isoschaftoside; 4: neoliquiritin; 5: liquiritin; 6: taxifolin; 7: liquiritigenin; 8: luteolin; 9: calycosin; 10: naringenin; 11: kaempferol; 12: formononetin; 13: licochalcone B; 14: echinatin; 15: isoliquiritigenin; 16: albiflorin; 17: paeoniflorin; 18: mudanpioside C; 19: benzoylpaeoniflorin; 20: glycyrrhizin; 21: hederagenin; 22: glycyrrhetinic acid; 23: 1,2,3,4,6-O-pentagalloylglucose.

\subsection{Cytotoxicity of JGTW in BEAS-2B and RAW264.7 Cells}

Next, we tested to see if JGTW have any effect on the viability and proliferation of pulmonary structural and effector cells. The human bronchial epithelial BEAS-2B cell was treated with various concentrations of the JGTW for $24 \mathrm{~h}$, then the proliferation and viability of these cells were measured. The JGTW did not show any significant cytotoxic effects even at the highest concentration (Figure 2). RAW264.7 cells were also treated with various concentrations of JGTW with or without $1 \mu \mathrm{g} / \mathrm{mL}$ LPS for $48 \mathrm{~h}$, then the viability of cells was measured. In accordance with the results of BEAS-2B, JGTW showed neither cytotoxic property nor cell proliferative activity to naïve RAW264.7 cells and LPSstimulated 264.7 cells up to $400 \mu \mathrm{g} / \mathrm{mL}$ (data not shown). 


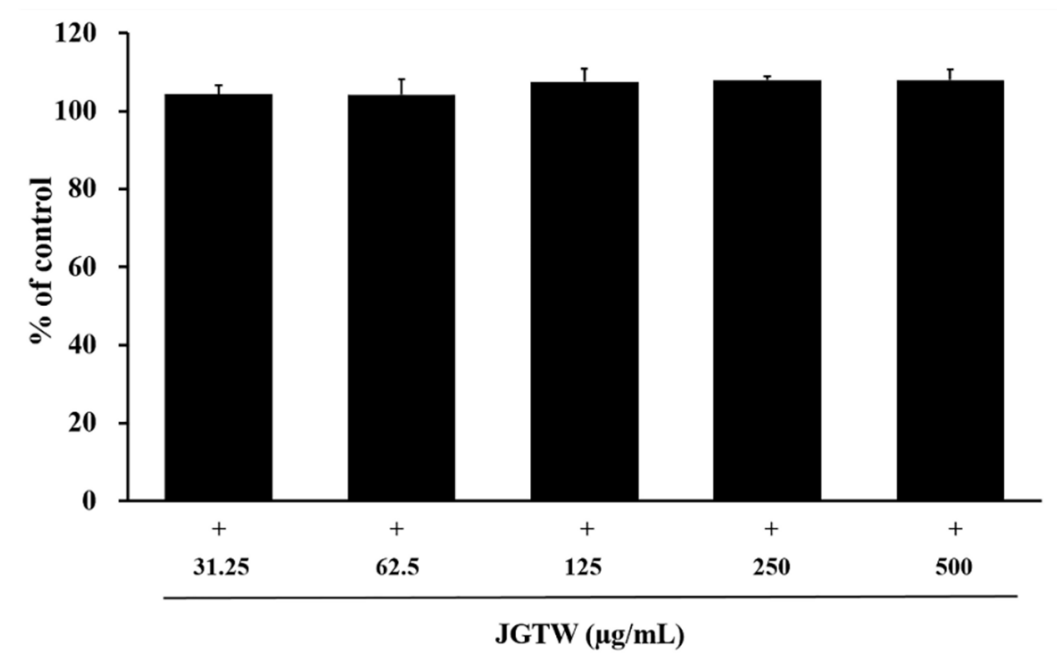

Figure 2. Cytotoxicity effect of JGTW in BEAS-2B cells. Cell viability after $24 \mathrm{~h} \mathrm{JGTW}$ treatment was assessed and the values are presented as mean \pm SEM.

\subsection{Effect of JGTW on CHEMOKINE Production}

ELISA was used to measure the contents of key inflammatory mediators in the pulmonary epithelial cell culture supernatant. As shown in Figure 3A,B, the concentration of eotaxin-1, eotaxin-3, and RANTES in the supernatant of IT-stimulated BEAS-2B cells were significantly higher than that in vehicle-treated cells $(p<0.01)$. However, treatment with 125,250 , and $500 \mu \mathrm{g} / \mathrm{mL}$ of JGTW significantly reduced the concentration of these chemokines dose dependently $(p<0.01)$.
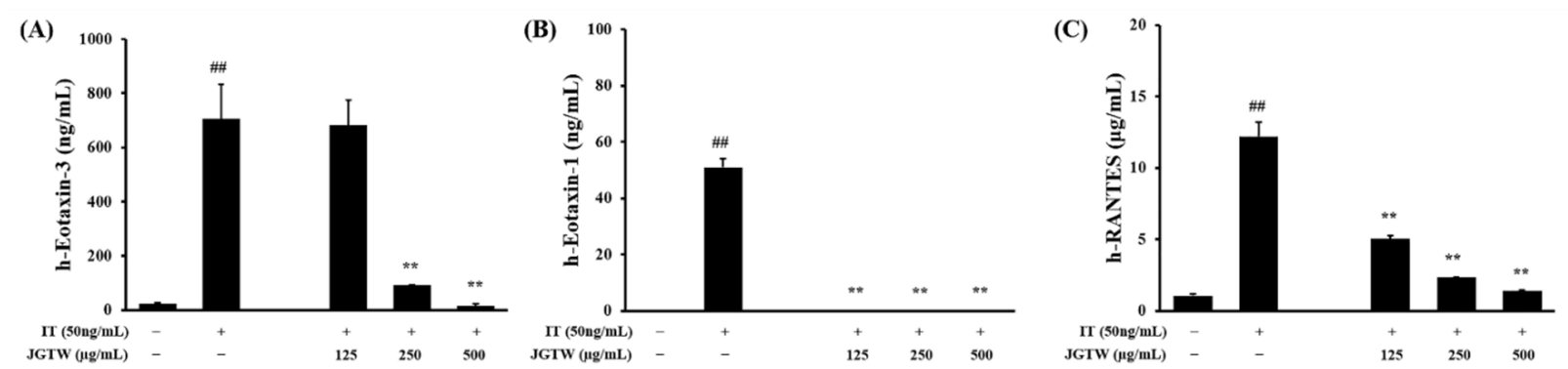

Figure 3. Effect of JGTW on the production of chemokines in BEAS-2B cells. The levels of h-eotaxin-3 (A) and h-eotaxin-1 (B) and h-RANTES (C) after $48 \mathrm{~h}$ IT (50 ng/mL) treatment with or without JGTW pretreatment in culture supernatants were measured. The values are presented as mean \pm SEM. ${ }^{\# \#} p<0.01$ versus vehicle-treated cells; and ${ }^{* *} p<0.01$ versus IT-treated cells.

\subsection{Effect of JGTW on MMP-9 Activity}

BEAS-2B cells were pretreated with various concentrations of JGTW and then stimulated with IT. The activities of MMP-9 and MMP-2 in cells increased after treatment with increased concentrations of IT (Figure 4A). Pretreatment with JGTW markedly reduced MMP-9 activity in a dose-proportional manner. Again, the ratio of MMP-9/MMP-2 was much higher in IT-stimulated cells as compared to that in vehicle-treated cells $(p<0.01)$ and JGTW pretreatment effectively decrease the ratio of MMP9/MMP-2 in IT-treated cells $(p<0.01$, Figure 4B). 
(A)

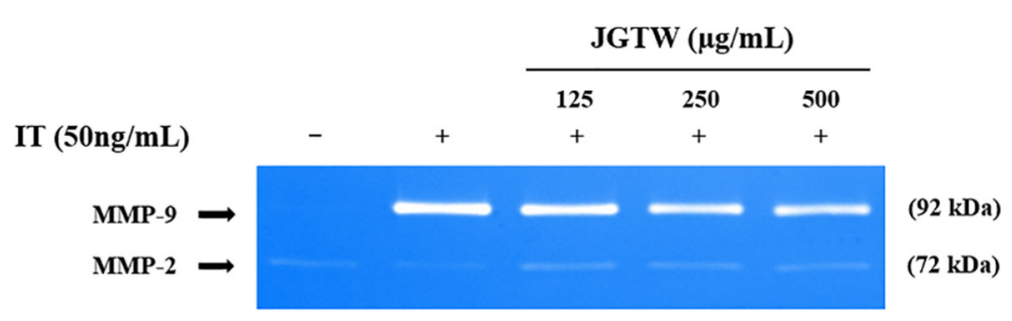

(B)

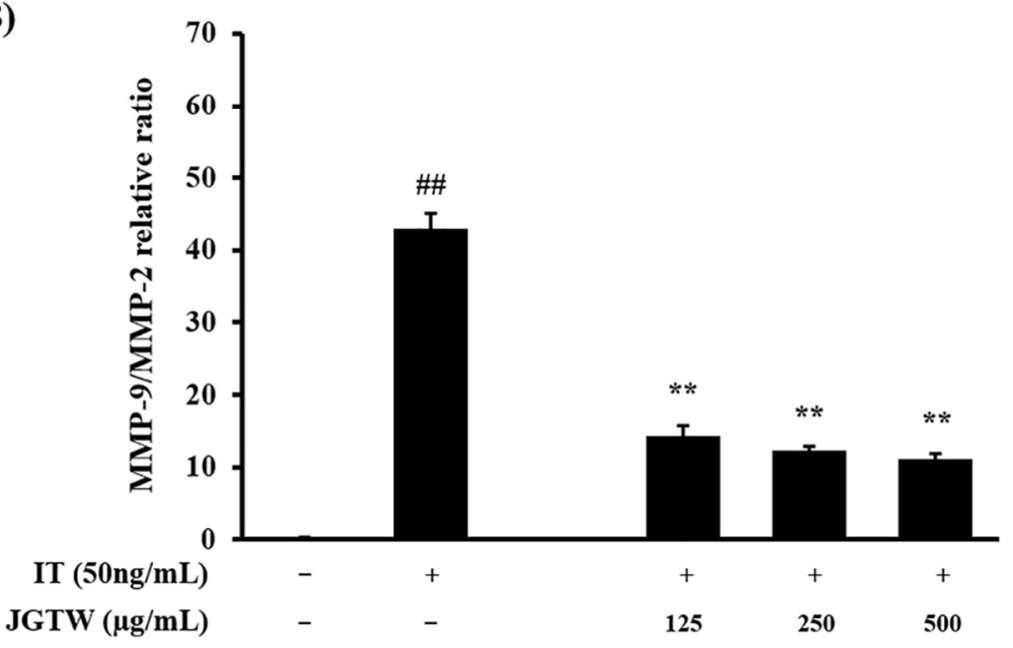

Figure 4. Effect of JGTW on the activity of MMP-9 in BEAS-2B cells. The representative photographs of MMP-9 activity after $48 \mathrm{~h}$ IT $(50 \mathrm{ng} / \mathrm{mL}$ ) treatment with or without JGTW pretreatment in gelatin zymography (A) and band intensities of MMP-9/MMP-2 (B). The values are presented as mean \pm SEM. ${ }^{\#} p<0.01$ versus vehicle-treated cells; and ${ }^{* *} p<0.01$ versus IT-treated cells.

\subsection{Effect of JGTW on Adhesion Molecules Expression}

After being stimulated with IT, the mRNA expression of ICAM-1 and VCAM-1 in BEAS-2B cells was markedly increased (Figure 5A,B). JGTW significantly suppressed IT-stimulated ICAM-1 and VCAM-1 expression proportionally over the doses $(p<0.01$, Figure 5C,D).

\subsection{Effect of JGTW on the iNOS Expression and NO Production}

To investigate the effect of JGTW on LPS-induced inflammatory responses, RAW264.7 cells were pretreated with various amounts of JGTW (6.25 to $100 \mu \mathrm{g} / \mathrm{mL}$ ) for $1 \mathrm{~h}$ and stimulated with $1 \mu \mathrm{g} / \mathrm{mL}$ LPS for $24 \mathrm{~h}$. Expression of iNOS was visualized using Western blot analysis. As shown in Figure 6A, iNOS expression was elevated with LPS stimulation, and pretreatment with JGTW suppressed iNOS overexpression in a dose-dependent manner. We also measured NO production from LPS-stimulated RAW264.7 cells with or without JGTW pretreatment. Furthermore, JGTW pretreatment had a suppressive effect on NO production induced by LPS showing statistically significant decrease at doses over $50 \mu \mathrm{g} / \mathrm{mL}$ (Figure 6B). 
(A)

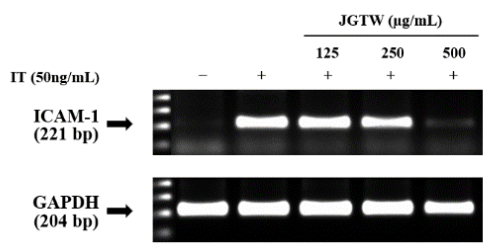

(C)

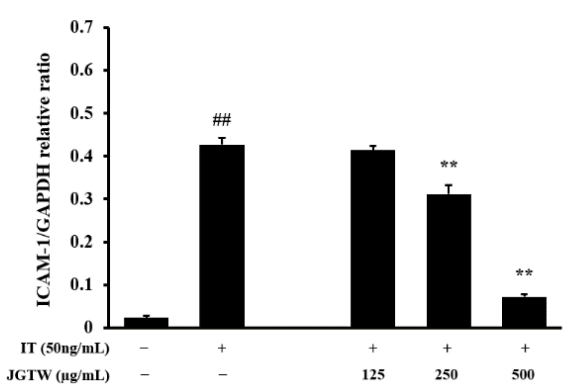

(B)

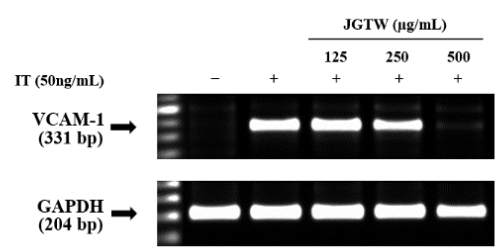

(D)

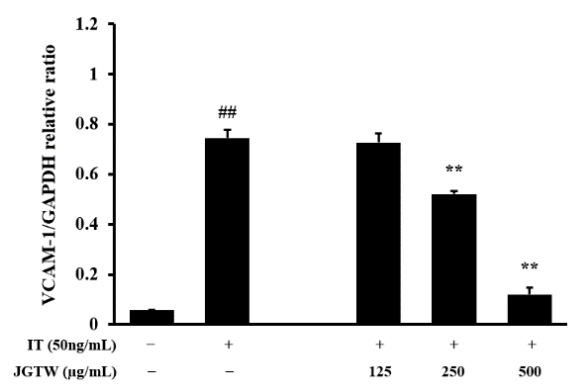

Figure 5. Effect of JGTW on the expression of adhesion molecules in BEAS-2B cells. RT-PCR was performed to analyze the expressions of ICAM-1 and VCAM-1 after $48 \mathrm{~h} \mathrm{IT}(50 \mathrm{ng} / \mathrm{mL})$ treatment with or without JGTW pretreatment in BEAS-2B cells. The representative photographs of ICAM-1 (A) or VCAM-1 (B) expressions, and band intensities of ICAM-1/GAPDH (C) or VCAM-1/GAPDH (D). The values are presented as mean \pm SEM. ${ }^{\# \#} p<0.01$ versus vehicle-treated cells; and ${ }^{* *} p<0.01$ versus IT-treated cells.

(A)

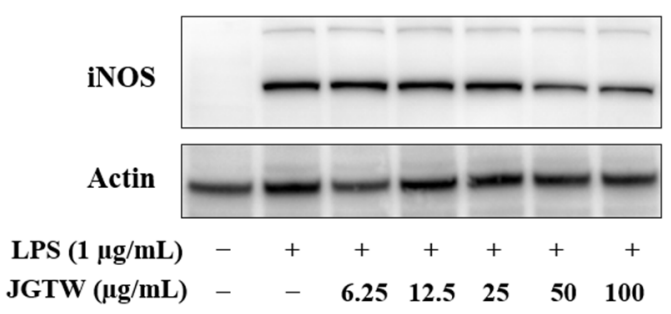

(B)

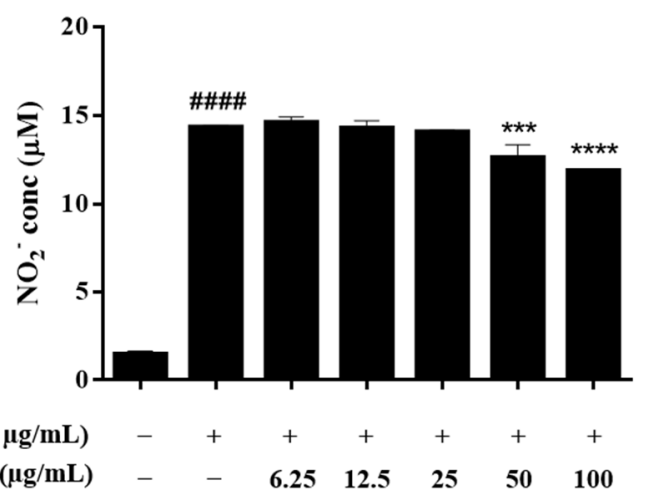

Figure 6. Effect of JGTW on the expression of iNOS and NO production in LPS-stimulated RAW264.7 cells. Cells were pretreated with JGTW (6.25 to $100 \mu \mathrm{g} / \mathrm{mL})$ and stimulated with LPS $(1 \mu \mathrm{g} / \mathrm{mL})$ for $24 \mathrm{~h}$. iNOS expression determined by Western blot analysis (A). Concentration of NO in the culture supernatant (B). The values are expressed as mean \pm SD. \#\#\#\# $p<0.0001$ versus vehicle-treated cells; ${ }^{* * *} p<0.001$ and ${ }^{* * * *} p<0.0001$ versus LPS -stimulated cells.

\subsection{Effect of JGTW on the LPS-Induced MAPK Activation and NF- $\kappa B$ Signaling}

To test whether this anti-inflammatory response of JGTW was mediated by the MAPKresponsive mechanism, the levels of p38 and ERK phosphorylation were evaluated in JGTW-treated and LPS-stimulated RAW264.7 cells. As presented in Figure 7A, RAW264.7 cells treated with LPS showed a significant increase in the phosphorylation of p38 and ERK, which was reduced by pretreatment of JGTW dose-dependently. We also examined the phosphorylation of JNK; however, the suppression of JNK phosphorylation by JGTW treatment was less significant compared to those of p38 and ERK (data not shown). 
(A)

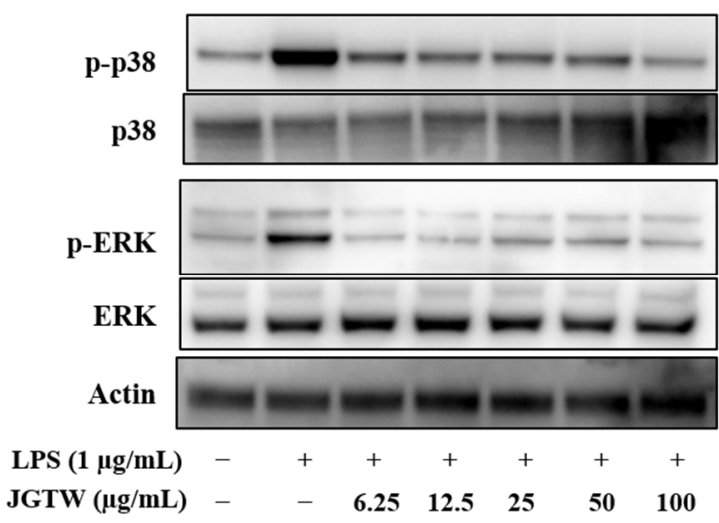

(B)

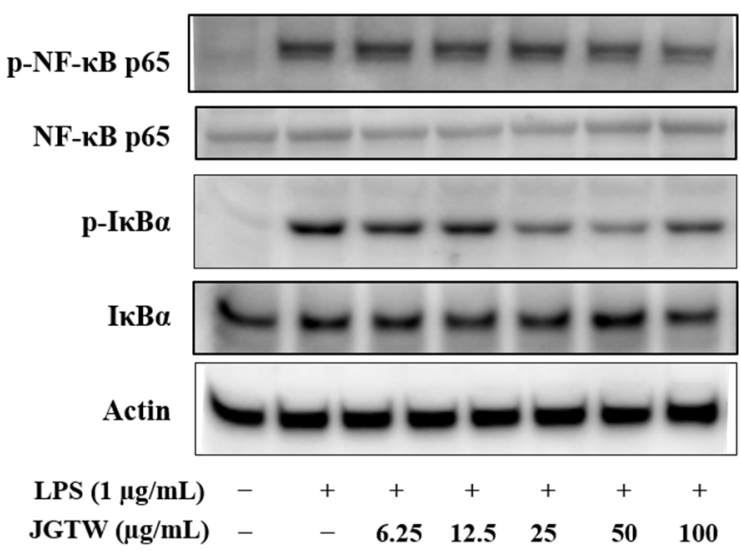

Figure 7. Effect of JGTW on LPS-stimulated activation of MAPK and NF-кB signaling in RAW264.7 cells. Cells were pretreated with JGTW (6.25 to $100 \mu \mathrm{g} / \mathrm{mL})$ and then stimulated with LPS ( $1 \mu \mathrm{g} / \mathrm{mL})$ for $24 \mathrm{~h}$. Total protein was isolated and the levels of p38 and ERK activation (A) and NF- $\mathrm{KB}$ and IKB activation (B) were determined by Western blot analysis.

It is well known that iNOS expression is mediated by the transcription factor NF- $\mathrm{kB}$. Consequently, the effect of JGTW on the phosphorylation of NF- $\mathrm{kB}$ subunit p65 and IкB- $\alpha$ was investigated. LPS-stimulated RAW264.7 cells showed a marked increase in phosphorylated NF- $\mathrm{kB}$ subunit $\mathrm{p} 65$ and IкB- $\alpha$; however, pretreatment with JGTW attenuated the increase of NFKB and IKB phosphorylation (Figure 7B).

\subsection{Effect of JGTW on Number of Inflammatory Cells}

We next evaluate the effect of JGTW on the pulmonary inflammation and allergic response in the OVA-induced asthmatic mouse model. To investigate the effect of JGTW on recruitment of inflammatory cells, we counted the total cell numbers in BALF. As shown in Figure 8, the number of inflammatory cells in BALF of OVA-treated group significantly increased compared with NC group $(p<0.01)$. In contrast, mice treated with JGTW (200 and $400 \mathrm{mg} / \mathrm{kg}, p<0.01)$ and Dex $(p<0.01)$ showed a significantly decreased number of inflammatory cells in BALF compared with OVA-treated mice (Figure 8).

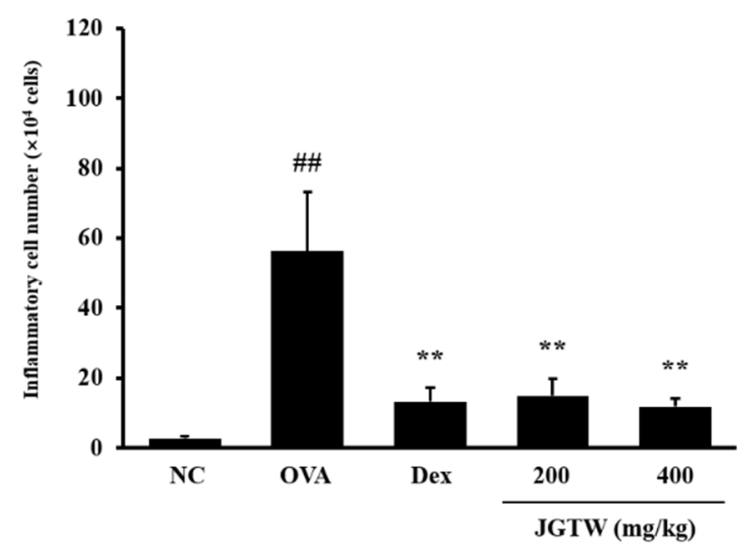

Figure 8. Effect of JGTW on number of inflammatory cells in OVA-induced mice. Number of BALF cell were counted using a light microscope with a hemocytometer. The values are presented as mean \pm SEM. ${ }^{\# \#} p<0.01$ versus NC group; and ${ }^{* *} p<0.01$ versus OVA-induced group.

\subsection{Effect of JGTW on Th2 Cytokines and IgE Levels}

To examine the effect of JGTW on Th2-type immune response, we measured the levels of Th2 cytokines and total IgE, and OVA-specific IgE in mouse models of asthma induced by OVA. The level of IL-5 and IL-13 in BALF were greatly elevated in the OVA group compared with NC group (IL-5; $p<0.05$, IL-13; not significant (ns)). However, JGTW 
(200 and $400 \mathrm{mg} / \mathrm{kg}$, ns) and Dex (ns) groups showed a tendency to decrease the levels of IL-5 (Figure 9A) and IL-13 (Figure 9B).

(A)

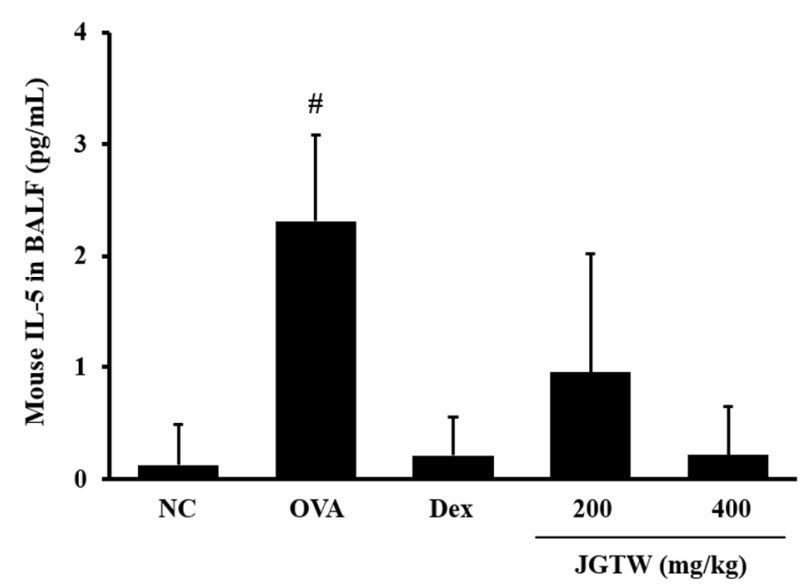

(C)

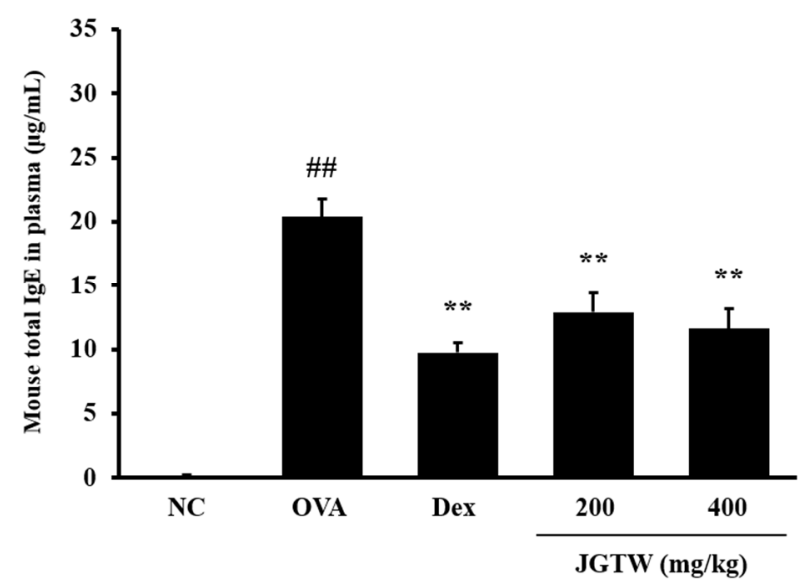

(B)

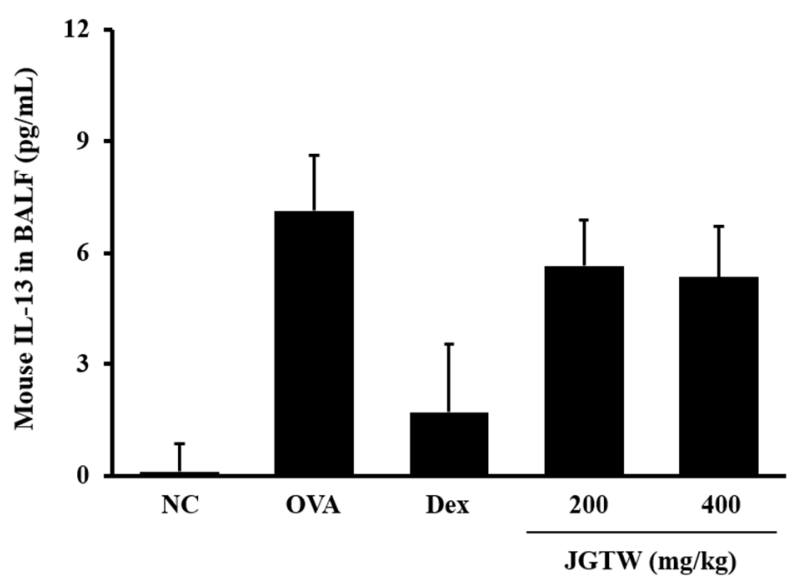

(D)

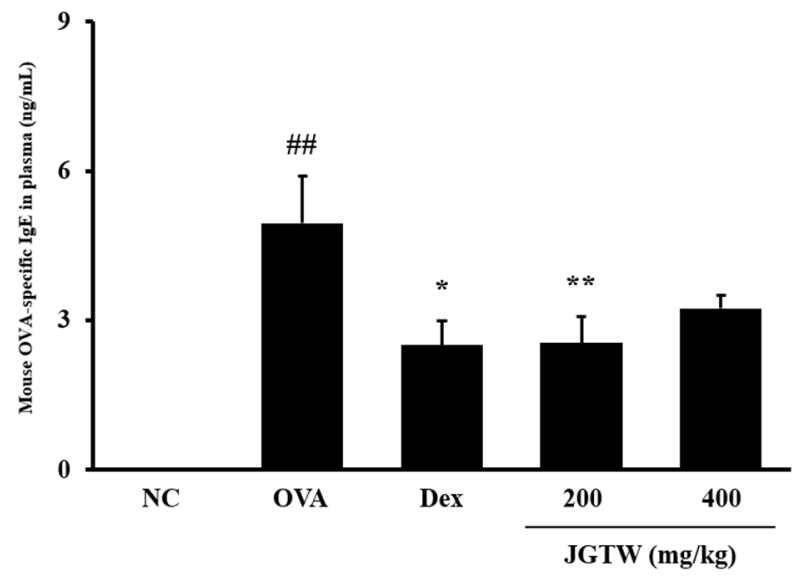

Figure 9. Effect of JGTW on Th2 cytokines and IgE levels in OVA-induced mice. The levels of Th2 cytokines and IgE were determined by ELISA kits. Th2 cytokines: IL-5 (A) and IL-13 (B). IgE: total IgE (C) and OVA-specific IgE (D). The values are presented as mean \pm SEM. ${ }^{\#} p<0.05$ or ${ }^{\# \#} p<0.01$ versus NC group; and ${ }^{*} p<0.05$ or ${ }^{* *} p<0.01$ versus OVA-induced group.

As shown in Figure 9 C,D, the levels of total and OVA-specific IgE in plasma were significantly increased in the OVA group compared with NC group $(p<0.01)$. However, the JGTW (200 and $400 \mathrm{mg} / \mathrm{kg}, p<0.01)$ and Dex $(p<0.01)$ groups significantly reduced the levels of total IgE. In addition, JGTW $(200 \mathrm{mg} / \mathrm{kg}, p<0.01)$ and Dex $(p<0.05)$ groups significantly inhibited the levels of OVA-specific IgE.

\section{Discussion}

Asthma is one of the most common and complex chronic respiratory disorder with airway inflammation as a main cause. Various types of tissues and cells are involved in the pathophysiology of asthma. Airway epithelial cells are the first barrier in the lung as opposed to foreign antigens inducing inflammation and when it fails, sustained inflammation can worsen the symptoms of asthma and result in exacerbation. Chemokines from airway epithelial cells, such as eotaxins and RANTES, have been described to contribute to chronic airway inflammation by recruiting macrophages, eosinophils, and Th cells at the site of inflammation [24-29].

In our study, JGTW demonstrated potent inhibitory effects on the generation of inflammatory chemokines in IT-stimulated BEAS-2B cells, a widely used in vitro model of airway epithelial cells. In addition, the JGTW treatment effectively suppressed MMP-9 activity, an 
enzyme that degrades extracellular matrix proteins, and infiltrating inflammatory effector cells $[30,31]$, in IT-stimulated BEAS-2B cells. It is a well-known fact that the increased expression of ICAM-1 and VCAM-1 on the respiratory epithelial cells is an important foundation of inflammatory cell infiltration into the inflamed airways [32], resulting in the development of asthma. JGTW treatment significantly suppressed the increased expression of these mediators in BEAS-2B cells stimulated with IT. Collectively, these findings demonstrated that JGTW had anti-inflammatory function acting through downregulation of pro-inflammatory soluble mediator expression, decreasing MMP-9 activity, resulting in lowered expression of adhesion molecules in a pulmonary epithelial cell model.

It is well known that eosinophils and mast cells are key players in the pathophysiology of asthma; however, evidence for the importance of macrophage-mediated inflammation in asthma is emerging $[8,9,33]$. High levels of macrophages are found in lung tissues in both asthma patients and mice with experimental asthma [33,34]. In our study, LPSstimulated RAW264.7 cells are used to mimic the inflammatory responses of macrophages. LPS treatment markedly increased iNOS expression, a widely used marker for inflammation, in RAW264.7 cells and pretreatment with JGTW for $1 \mathrm{~h}$ efficiently blocked this elevated expression of iNOS. In line with this result, JGTW also suppressed nitrite production in LPS-stimulate RAW264.7 cells. It is also reported that JGTW significantly decreased prostaglandin E2 production via suppressing COX-2, IL-1 $\beta$, and IL-6, which are known mediators of airway inflammation in asthma [13]. Collectively, our data and others suggested that JGTW alleviates the inflammatory response by reducing various mediators such as iNOS, COX2, and cytokine expression.

It is known that the MAPK and NF- $\mathrm{kB}$ signaling pathways are an important part in mediating the pathophysiology of asthma, and these signaling pathways are also associated with the activation of effector cells during inflammation [35,36]. Hence, the inhibitory effect of JGWT on aberrant MAPK activation in LPS-stimulated RAW264.7 cells was assessed. JGTW efficiently suppressed the phosphorylation of p38 and ERK. Furthermore, JGTW exerted an inhibitory effect on the activation of NF-kB signaling, showing decreased expression of phosphorylated-NF- $\kappa B$ p 65 subunit and $I \kappa B \alpha$. These results suggest that the inhibition of iNOS expression and anti-inflammatory properties by JGTW is mediated via suppression of NF- $\mathrm{KB}$ activation at least partly through p38 and ERK suppression. In our data, suppression of ERK is more effective in lower doses of JGTW treatment, which is occasionally observed result that the lower dose of herbal extract is more effective in regulating signaling pathway. This might be due to the combinational effect of various compounds of JGTW; hence, further studies regarding the active compound responsible for inhibiting MAPK pathway should be done.

OVA-sensitized and challenged mice represented typical asthmatic features such as increased inflammatory cell recruitment and elevated IgE level. In the present study, JGTW treatment after OVA sensitization effectively reduced the number of inflammatory cells in BALF, suggesting the effectiveness of anti-inflammatory response by JGTW shown in vitro on relieving symptoms of asthma in animal model. Additionally, the levels of IL-5 and IL-13 in BALF, a hallmark of Th2 response in asthma, which were elevated in response to the OVA treatment, showed a tendency to decrease by JGTW treatment. Furthermore, plasma levels of IgE, both total and OVA-specific, in JGTW treated mice were significantly lower than those of OVA-induced mice. Collectively, these results suggest that JGTW suppresses the inflammatory and allergic responses associated with asthma.

As previously mentioned, JGT is composed of two herbal ingredients, P. lactiflora and G. uralensis, and their chemical constituents mainly include flavonoids (e.g., flavones, flavanones, flavonoid glycosides), terpenoids (e.g., monoterpenes, monoterpene glycosides, triterpenes), and chalcones [22,23]. In this study, UPLC-DAD-MS/MS analysis was performed to identify and quantify the 24 phytochemicals in JGTW, comprising 12 flavonoids (catechin, vicenin-2, schaftoside, isoschaftoside, neoliquiritin, liquiritin, taxifolin, liquiritigenin, luteolin, calycosin, naringenin, kaempferol, and formononetin), three chalcones (licochalcone B, echinatin, and isoliquiritigenin), seven terpenoids (albiflorin, paeoni- 
florin, mudanpioside $C$, benzoylpaeoniflorin, glycyrrhizin, hederagenin, and glycyrrhetinic acid), and one phenol (1,2,3,4,6-O-pentagalloylglucose), and paeoniflorin $(63.971 \mathrm{mg} / \mathrm{g})$ from P. lactiflora and glycyrrhizin $(11.853 \mathrm{mg} / \mathrm{g})$ from G. uralensis were abundantly found in JGTW.

The individual herbal compounds that constitute JGT have been reported to be effective against airway inflammation-related diseases, such as asthma. Paeoniflorin, a major component of $P$. lactiflora, exerts anti-asthmatic effects by modulating the Th1/Th2 equilibrium [37] and inhibiting the growth and migration of airway smooth muscle cells [38]. Total glucosides of $P$. lactiflora improve ovalbumin-induced allergic asthma in mice by suppressing mast cell degranulation [39]. Glycyrrhizin, a major component of G. uralensis, alleviates asthmatic symptoms in mice [40] and ameliorates the chronic histopathological changes in the lungs of mice suffering from asthma [41] and asthmatic progression through modulation of Th1/Th2 cytokines and enhancement of $\mathrm{CD} 4^{+} \mathrm{CD} 25^{+} \mathrm{Foxp} 3^{+}$ Tregs [42]. In addition, components of G. uralensis, isoliquiritigenin and licochalcone A, relax guinea pig tracheal smooth muscle in vitro and in vivo [43] and alleviate oxidative stress and hyper-responsiveness in asthmatic mice [44], respectively. These previous studies and our quantitative analysis data for the phytochemicals in JGTW suggest that the anti-inflammatory activity of JGTW in IT-stimulated BEAS-2B and LPS-stimulated RAW264.7 cells may be attributed to paeoniflorin and glycyrrhizin.

In summary, our results discovered that JGTW might exert anti-inflammatory effects by suppressing the airway inflammation-related factors in pulmonary epithelial cells and macrophages. JGTW also demonstrates potency in reducing inflammatory cell recruitment and allergic response in the OVA-induced asthmatic mouse model, suggesting the clinical effectiveness of JGT on relieving symptoms of asthma. In addition, paeoniflorin and glycyrrhizin were abundantly present in JGTW, which might contribute to its antiinflammatory effects. Follow-up studies on identifying the bioactive compounds that inhibit airway inflammation would be necessary to develop a new therapeutic option for asthma utilizing traditionally used herbal medicine.

Supplementary Materials: The following is available online at https://www.mdpi.com/article/ 10.3390/app112210569/s1, Figure S1: Comparison of mass spectrum of reference standards and JGTW constituents.

Author Contributions: Conceptualization, M.-Y.L., Y.-H.H. and J.K.; investigation, Y.J.K., W.-Y.J. and J.K.; writing — original draft preparation, Y.J.K., W.-Y.J. and J.K.; writing—review and editing, M.-Y.L., Y.-H.H. and J.K.; supervision, J.K.; project administration, M.-Y.L.; funding acquisition, M.-Y.L. All authors have read and agreed to the published version of the manuscript.

Funding: The funding source of this research is grant number KSN2021220 by the Korea Institute of Oriental Medicine.

Institutional Review Board Statement: Not applicable.

Informed Consent Statement: Not applicable.

Data Availability Statement: The data presented in this study are available within the article.

Acknowledgments: We thank the KM Convergence Research Division, Korea Institute of Oriental Medicine, for the distribution of the plant material.

Conflicts of Interest: The authors declare no conflict of interest. 


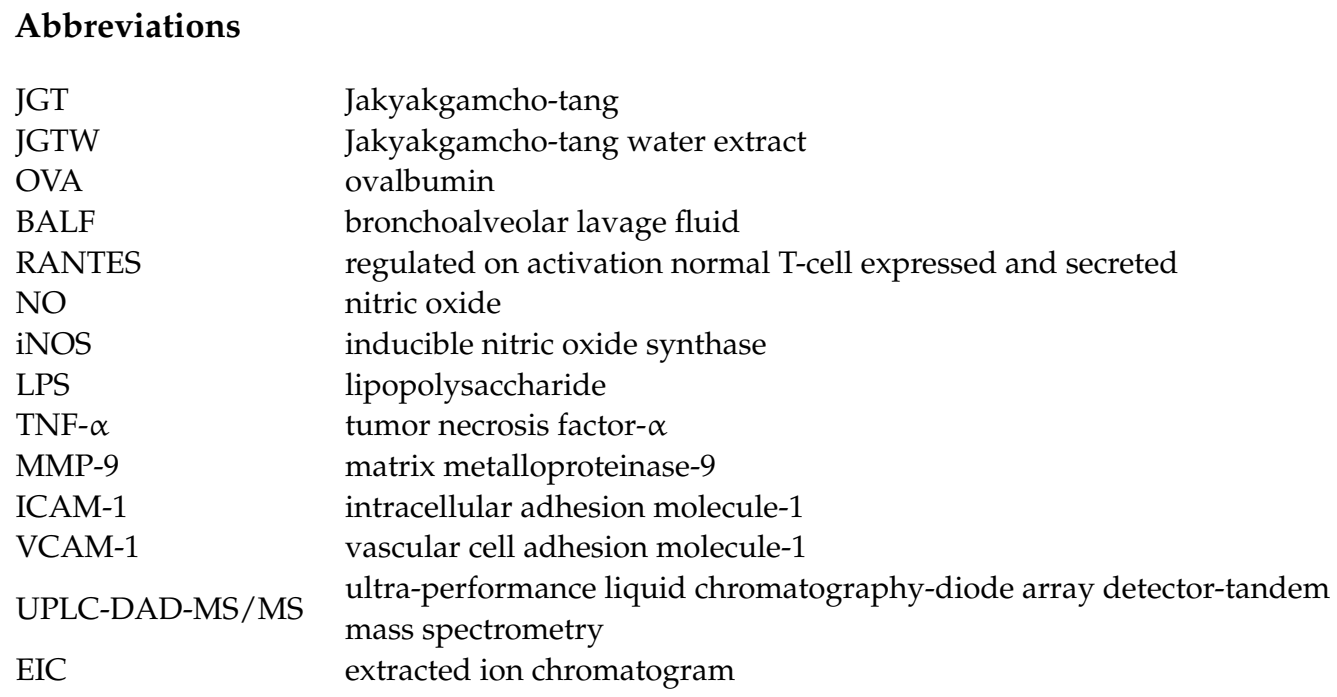

\section{References}

1. Lee, N.H.; Lee, M.Y.; Lee, J.A.; Jung, D.Y.; Seo, C.S.; Kim, J.H.; Shin, H.K. Anti-asthmatic effect of Sanguisorba officinalis L. and potential role of heme oxygenase-1 in an ovalbumin-induced murine asthma model. Int. J. Mol. Med. 2010, 26, 201-208. [CrossRef] [PubMed]

2. Lee, M.Y.; Lee, J.A.; Seo, C.S.; Ha, H.; Lee, N.H.; Shin, H.K. Protective effects of Mentha haplocalyx ethanol extract (MH) in a mouse model of allergic asthma. Phytother. Res. 2011, 25, 863-869. [CrossRef] [PubMed]

3. Ricciardolo, F.L.; Sterk, P.J.; Gaston, B.; Folkerts, G. Nitric oxide in health and disease of the respiratory system. Physiol. Rev. 2004, 84, 731-765. [CrossRef] [PubMed]

4. Williams, C.M.; Galli, S.J. Mast cells can amplify airway reactivity and features of chronic inflammation in an asthma model in mice. J. Exp. Med. 2000, 192, 455-462. [CrossRef] [PubMed]

5. Corbel, M.; Boichot, E.; Lagente, V. Role of gelatinases MMP-2 and MMP-9 in tissue remodeling following acute lung injury. Braz. J. Med. Biol. Res. 2000, 33, 749-754. [CrossRef] [PubMed]

6. Rosseau, S.; Selhorst, J.; Wiechmann, K.; Leissner, K.; Maus, U.; Mayer, K.; Grimminger, F.; Seeger, W.; Lohmeyer, J. Monocyte migration through the alveolar epithelial barrier: Adhesion molecule mechanisms and impact of chemokines. J. Immunol. 2000, 164, 427-435. [CrossRef]

7. Lee, K.S.; Jin, S.M.; Kim, H.J.; Lee, Y.C. Matrix metalloproteinase inhibitor regulates inflammatory cell migration by reducing ICAM-1 and VCAM-1 expression in a murine model of toluene diisocyanate-induced asthma. J. Allergy Clin. Immunol. 2003, 111, 1278-1284. [CrossRef] [PubMed]

8. Fehervari, Z. Alveolar macrophages in asthma. Nat. Immunol. 2015, 16, 64. [CrossRef]

9. Lee, Y.G.; Jeong, J.J.; Nyenhuis, S.; Berdyshev, E.; Chung, S.; Ranjan, R.; Karpurapu, M.; Deng, J.; Qian, F.; Kelly, E.A.; et al. Recruited alveolar macrophages, in response to airway epithelial-derived monocyte chemoattractant protein $1 / \mathrm{CCl} 2$, regulate airway inflammation and remodeling in allergic asthma. Am. J. Respir. Cell Mol. Biol. 2015, 52, 772-784. [CrossRef]

10. Hinoshita, F.; Ogura, Y.; Suzuki, Y.; Hara, S.; Yamada, A.; Tanaka, N.; Yamashita, A.; Marumo, F. Effect of orally administered shao-yao-gan-cao-tang (Shakuyaku-kanzo-to) on muscle cramps in maintenance hemodialysis patients: A preliminary study. Am. J. Chin. Med. 2003, 31, 445-453. [CrossRef]

11. Hyodo, T.; Taira, T.; Takemura, T.; Yamamoto, S.; Tsuchida, M.; Yoshida, K.; Uchida, T.; Sakai, T.; Hidai, H.; Baba, S. Immediate effect of Shakuyaku-kanzo-to on muscle cramp in hemodialysis patients. Nephron. Clin. Pract. 2006, 104, c28-c32. [CrossRef]

12. Tsuji, S.; Yasuda, K.; Sumi, G.; Cho, H.; Tsuzuki, T.; Okada, H.; Kanzaki, H. Shakuyaku-kanzo-to inhibits smooth muscle contractions of human pregnant uterine tissue in vitro. J. Obstet. Gynaecol. Res. 2012, 38, 1004-1010. [CrossRef] [PubMed]

13. Lee, Y.M.; Kim, D.S. The Extraction Solvent Influences the Anti-Inflammatory Effects of Jakyakgamcho-Tang in LipopolysaccharideStimulated Macrophages and Mice with Gouty Arthritis. Int. J. Mol. Sci. 2020, 21, 9748. [CrossRef]

14. Seo, S.H.; Unno, T.; Park, S.E.; Kim, E.J.; Lee, Y.M.; Na, C.S.; Son, H.S. Korean Traditional Medicine (Jakyakgamcho-tang) Ameliorates Colitis by Regulating Gut Microbiota. Metabolites 2019, 9, 226. [CrossRef] [PubMed]

15. Hidaka, T.; Shima, T.; Nagira, K.; Ieki, M.; Nakamura, T.; Aono, Y.; Kuraishi, Y.; Arai, T.; Saito, S. Herbal medicine Shakuyakukanzo-to reduces paclitaxel-induced painful peripheral neuropathy in mice. Eur. J. Pain 2009, 13, 22-27. [CrossRef]

16. Kim, J.; Kim, C.S.; Kim, Y.S.; Lee, I.S.; Kim, J.S. Jakyakgamcho-tang and Its Major Component, Paeonia Lactiflora, Exhibit Potent Anti-glycation Properties. J. Exerc. Nutr. Biochem. 2016, 20, 60-64. [CrossRef]

17. Han, K.; Kwon, O.; Jung, S.Y.; Park, I.H.; Hwang, M.S.; Park, S.Y.; Hwang, E.H.; Lee, J.H. Jakyakgamcho-tang in the relief of delayed-onset muscle soreness in healthy adults: Study protocol for a randomized, double-blind, placebo-controlled, crossover design clinical trial. Trials 2020, 21, 211. [CrossRef] [PubMed] 
18. He, F.; Xu, J.; Yang, M.H.; Ru, C.H.; Shen, X.Q.; Wu, B.; Cai, W.R. Influence of Shaoyao Gancao Decoction on ratio of Treg/Th17 in rats with asthma. Chin. J. Tradit. Chin. Med. Pharm. 2016, 31, 4477-4479.

19. Jeong, S.J.; Lim, H.S.; Seo, C.S.; Kim, J.H.; Jin, S.E.; Yoo, S.R.; Shin, H.K. Traditional herbal formula Jakyakgamcho-tang (Paeonia lactiflora and Glycyrrhiza uralensis) impairs inflammatory chemokine production by inhibiting activation of STAT1 and NF- $\mathrm{KB}$ in HaCaT cells. Phytomedicine 2015, 22, 326-332. [CrossRef]

20. Zhu, G.-W.; Guo, J.; Li, Y.-J.; Luo, L.; Sugita, T.; Tomoda, T. The effect of peony and licorice decoction on the voltage-gated sodium channel subtype 1.4 based on standard decoction. World J. Tradit. Chin. Med. 2018, 4, 69-76. [CrossRef]

21. Kim, Y.J.; Jeon, W.Y.; Hwang, Y.H.; Lee, M.Y. Inhibitory Effects of Gyeji-Tang on MMP-9 Activity and the Expression of Adhesion Molecules in IL-4- and TNF- $\alpha$-Stimulated BEAS-2B Cells. Plants 2021, 10, 951. [CrossRef]

22. Zhou, J.X.; Braun, M.S.; Wetterauer, P.; Wetterauer, B.; Wink, M. Antioxidant, Cytotoxic, and Antimicrobial Activities of Glycyrrhiza glabra L., Paeonia lactiflora Pall., and Eriobotrya japonica (Thunb.) Lindl. Extracts. Medicines 2019, 6, 43. [CrossRef]

23. Choung, M.-G. Variation of Bioactive Component Contents in Plant Parts of Paeonia lactiflora Pall. Korean J. Med. Crop. Sci. 2002, 10, 392-398.

24. Matsukura, S.; Osakabe, Y.; Sekiguchi, A.; Inoue, D.; Kakiuchi, Y.; Funaki, T.; Yamazaki, Y.; Takayasu, H.; Tateno, H.; Kato, E.; et al. Overexpression of microRNA-155 suppresses chemokine expression induced by Interleukin-13 in BEAS-2B human bronchial epithelial cells. Allergol. Int. 2016, 65, 17-23. [CrossRef] [PubMed]

25. Jose, P.J.; Griffiths-Johnson, D.A.; Collins, P.D.; Walsh, D.T.; Moqbel, R.; Totty, N.F.; Truong, O.; Hsuan, J.J.; Williams, T.J. Eotaxin: A potent eosinophil chemoattractant cytokine detected in a guinea pig model of allergic airways inflammation. J. Exp. Med. 1994, 179, 881-887. [CrossRef]

26. Forssmann, U.; Uguccioni, M.; Loetscher, P.; Dahinden, C.A.; Langen, H.; Thelen, M.; Baggiolini, M. Eotaxin-2, a novel CC chemokine that is selective for the chemokine receptor CCR3, and acts like eotaxin on human eosinophil and basophil leukocytes. J. Exp. Med. 1997, 185, 2171-2176. [CrossRef]

27. Kitaura, M.; Suzuki, N.; Imai, T.; Takagi, S.; Suzuki, R.; Nakajima, T.; Hirai, K.; Nomiyama, H.; Yoshie, O. Molecular cloning of a novel human CC chemokine (Eotaxin-3) that is a functional ligand of CC chemokine receptor 3. J. Biol. Chem. 1999, 274, 27975-27980. [CrossRef] [PubMed]

28. Provost, V.; Larose, M.C.; Langlois, A.; Rola-Pleszczynski, M.; Flamand, N.; Laviolette, M. CCL26/eotaxin-3 is more effective to induce the migration of eosinophils of asthmatics than CCL11/eotaxin-1 and CCL24/eotaxin-2. J. Leukoc. Biol. 2013, 94, 213-222. [CrossRef] [PubMed]

29. Alam, R.; Stafford, S.; Forsythe, P.; Harrison, R.; Faubion, D.; Lett-Brown, M.A.; Grant, J.A. RANTES is a chemotactic and activating factor for human eosinophils. J. Immunol. 1993, 150, 3442-3448. [PubMed]

30. Brand, K.H.; Ahout, I.M.; de Groot, R.; Warris, A.; Ferwerda, G.; Hermans, P.W. Use of MMP-8 and MMP-9 to assess disease severity in children with viral lower respiratory tract infections. J. Med. Virol. 2012, 84, 1471-1480. [CrossRef] [PubMed]

31. Malla, N.; Sjøli, S.; Winberg, J.O.; Hadler-Olsen, E.; Uhlin-Hansen, L. Biological and pathobiological functions of gelatinase dimers and complexes. Connect. Tissue Res. 2008, 49, 180-184. [CrossRef]

32. Nakajima, H.; Sano, H.; Nishimura, T.; Yoshida, S.; Iwamoto, I. Role of vascular cell adhesion molecule 1/very late activation antigen 4 and intercellular adhesion molecule 1/lymphocyte function-associated antigen 1 interactions in antigen-induced eosinophil and T cell recruitment into the tissue. J. Exp. Med. 1994, 179, 1145-1154. [CrossRef]

33. van der Veen, T.A.; de Groot, L.E.S.; Melgert, B.N. The different faces of the macrophage in asthma. Curr. Opin. Pulm. Med. 2020, 26, 62-68. [CrossRef]

34. Lee, J.W.; Min, J.H.; Kim, M.G.; Kim, S.M.; Kwon, O.K.; Oh, T.K.; Lee, J.K.; Kim, T.Y.; Lee, S.W.; Choi, S.; et al. Pistacia weinmannifolia root exerts a protective role in ovalbumin-induced lung inflammation in a mouse allergic asthma model. Int. J. Mol. Med. 2019, 44, 2171-2180. [CrossRef] [PubMed]

35. Nguyen, T.H.; Maltby, S.; Simpson, J.L.; Eyers, F.; Baines, K.J.; Gibson, P.G.; Foster, P.S.; Yang, M. TNF- $\alpha$ and Macrophages Are Critical for Respiratory Syncytial Virus-Induced Exacerbations in a Mouse Model of Allergic Airways Disease. J. Immunol. 2016, 196, 3547-3558. [CrossRef]

36. Yuk, H.J.; Lee, J.W.; Park, H.A.; Kwon, O.-K.; Seo, K.-H.; Ahn, K.-S.; Oh, S.-R.; Ryu, H.W. Protective effects of coumestrol on lipopolysaccharide-induced acute lung injury via the inhibition of proinflammatory mediators and NF- $\mathrm{kB}$ activation. J. Funct. Foods 2017, 34, 181-188. [CrossRef]

37. Zhang, T.; Yang, Z.; Yang, S.; Du, J.; Wang, S. Immunoregulatory Effects of Paeoniflorin Exerts Anti-asthmatic Effects via Modulation of the Th1/Th2 Equilibrium. Inflammation 2015, 38, 2017-2025. [CrossRef] [PubMed]

38. Zhou, H.; Wu, Q.; Wei, L.; Peng, S. Paeoniflorin inhibits PDGF-BB-induced human airway smooth muscle cell growth and migration. Mol. Med. Rep. 2018, 17, 2660-2664. [CrossRef]

39. Shou, Q.; Lang, J.; Jin, L.; Fang, M.; Cao, B.; Cai, Y.; Ni, Z.; Qiu, F.; Li, C.; Cao, G.; et al. Total glucosides of peony improve ovalbumin-induced allergic asthma by inhibiting mast cell degranulation. J. Ethnopharmacol. 2019, 244, 112136. [CrossRef]

40. Ram, A.; Mabalirajan, U.; Das, M.; Bhattacharya, I.; Dinda, A.K.; Gangal, S.V.; Ghosh, B. Glycyrrhizin alleviates experimental allergic asthma in mice. Int. Immunopharmacol. 2006, 6, 1468-1477. [CrossRef]

41. Hocaoglu, A.B.; Karaman, O.; Erge, D.O.; Erbil, G.; Yilmaz, O.; Bagriyanik, A.; Uzuner, N. Glycyrrhizin and long-term histopathologic changes in a murine model of asthma. Curr. Ther. Res. Clin. Exp. 2011, 72, 250-261. [CrossRef] [PubMed] 
42. Ma, C.; Ma, Z.; Liao, X.L.; Liu, J.; Fu, Q.; Ma, S. Immunoregulatory effects of glycyrrhizic acid exerts anti-asthmatic effects via modulation of Th1/Th2 cytokines and enhancement of CD4(+)CD25(+)Foxp3+ regulatory T cells in ovalbumin-sensitized mice. J. Ethnopharmacol. 2013, 148, 755-762. [CrossRef] [PubMed]

43. Liu, B.; Yang, J.; Wen, Q.; Li, Y. Isoliquiritigenin, a flavonoid from licorice, relaxes guinea-pig tracheal smooth muscle in vitro and in vivo: Role of cGMP/PKG pathway. Eur. J. Pharmacol. 2008, 587, 257-266. [CrossRef] [PubMed]

44. Huang, W.C.; Liu, C.Y.; Shen, S.C.; Chen, L.C.; Yeh, K.W.; Liu, S.H.; Liou, C.J. Protective Effects of Licochalcone A Improve Airway Hyper-Responsiveness and Oxidative Stress in a Mouse Model of Asthma. Cells 2019, 8, 617. [CrossRef] 